\title{
SOME ASPECTS OF IN VITRO ACTIVITIES OF KANAMYCIN AGAINST TUBERCLE BACILLI
}

According to Yanagisawa and Sato (1957), kanamycin inhibits the growth of tubercle bacilli in Kirchner's or tween-albumin liquid medium in the concentration of $1 \mu \mathrm{g}$ or so. This type of in vitro activity is, in most cases, considered as the bacteriostatic effect. Therefore, our further experimental interest in in vitro activities of kanamycin is principally concerned with the problems whether this antibiotic has bactericidal effect or not, and whether tubercle bacilli resistant to kanamycin could occur or not. In this connection, the present authors conducted some preliminary attempts on these aspects.

Sauton synthetic liquid medium was dispensed to 22 Erlenmyer flasks of $100 \mathrm{cc}$ capacity in the amount of $27 \mathrm{cc}$. These flasks were seeded uniformly with a certain size of pellicle obtained by dividing a 16 day surface growth of tubercle bacilli (Aoyama B strain) on Sauton medium. They were incubated at $37^{\circ} \mathrm{C}$ for 12 days and a pellicle growth developed vigorously in them. Then, 7 flasks of them were added with $3 \mathrm{cc}$ of kanamycin solution to make its final concentration $100 \mu \mathrm{g}$ per cc in terms of free base, another 7 flasks were also added with $3 \mathrm{cc}$ of streptomycin solution to make the same drug concentration as above, and still another 7 flasks were added with $3 \mathrm{cc}$ of distilled water to serve as controls. All the flasks were further incubated at $37^{\circ} \mathrm{C}$. Pellicle growth in remaining one flask was harvested on a funnel and washed with distilled water until the filtrate became completely colorless. The bacillary mass thus obtained was then placed between the layered folds of absorbent filter paper to be pressed and deprived of the moisture. A portion of this semi-dried material was weighed and put into a $500 \mathrm{cc}$ round flask containing 60 crystal balls of $7 \mathrm{~mm}$ diameter. Rotating it manually with occasional adding of a 1/15 Mol. phosphate buffer solution ( $\mathrm{pH} \mathrm{6.9),} \mathrm{the} \mathrm{bacillary} \mathrm{mass} \mathrm{was} \mathrm{ground} \mathrm{to} \mathrm{obtain} \mathrm{a} \mathrm{homogeneous} 1 \mathrm{mg}$ per cc suspension. Then, by a routine diluting and planting method, the number of viable bacterial units contained in $1 \mathrm{mg}$ of the bacterial mass was enumerated. This mode of viability test was conducted also concerning the kanamycin, streptomycin and control flasks incubated for $1,2,3,5,6,7$ and 8 days at $37^{\circ} \mathrm{C}$ after the addition of test materials, each time using one flask respectively. The results are presented graphically in Fig. 1. The figure shows that kanamycin had a certain grade of bactericidal activity, being inferior to streptomycin when compared in the same $100 \mu \mathrm{g}$ per cc concentration, and that this effect became stationary after three days' contact.

The next experiment was the same as the previous one in principle, but 
the bacillary culture was made in two separation funnels containing 300 ce Sauton medium. Six days after seeding, pellicle formation developed vigorously in just the same grade in both funnels. Then, kanamycin was added into one of these

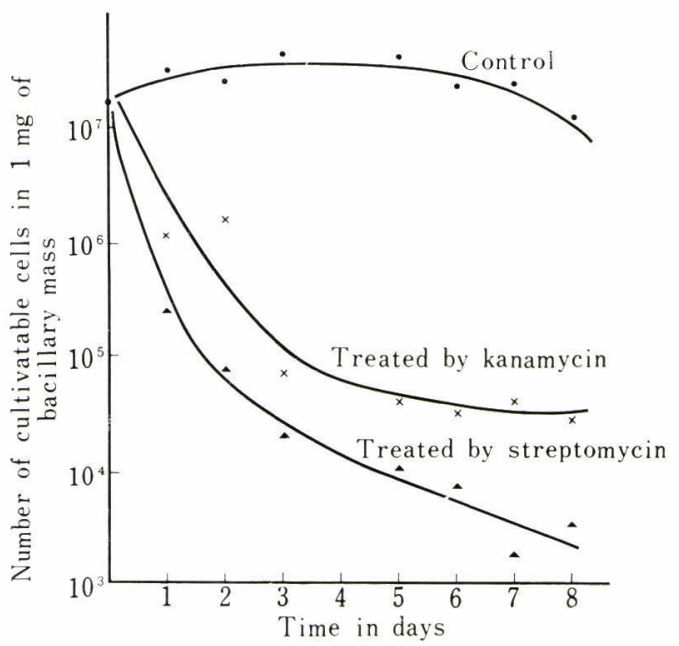

Fig. 1. A comparative observation of bactericidal effect of kanamycin and streptomycin against tubercle bacilli.

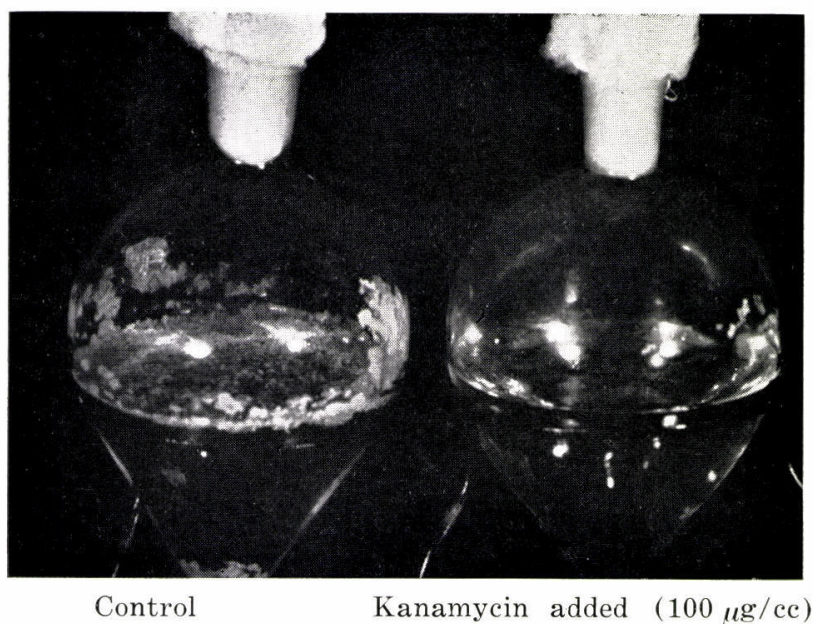

Fig. 2. Photographic demonstration of kanamycin effect upon Sauton culture of tubercle bacilli.

funnels to make its final concentration $100 \mu \mathrm{g}$ per cc. Incubation at $37^{\circ} \mathrm{C}$ was continued for additional 8 days. Then, the amount of total growth and viability of two cultures were examined in just the same method as described before, and change of $\mathrm{pH}$ of the medium was pursued during this experimental period ex- 


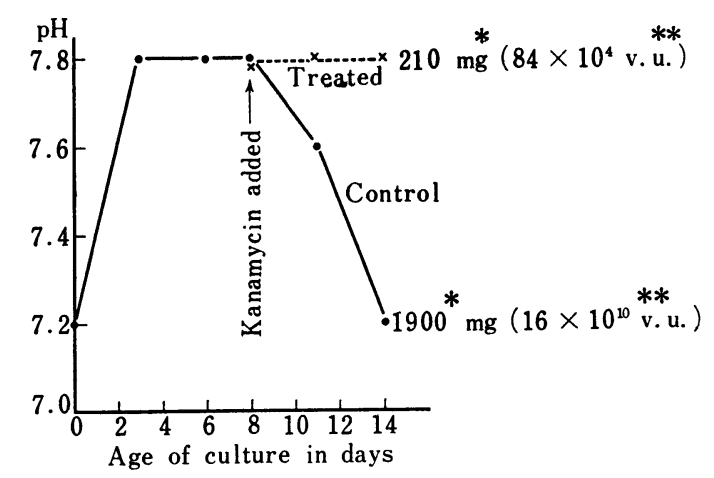

Fig. 3. Effects of kanamycin upon Sauton culture of tubercle bacilli with reference to total yield, viability and change of medium $\mathrm{pH}$.

Note: * Total yield

** Number of viable bacterial units contained in total yield

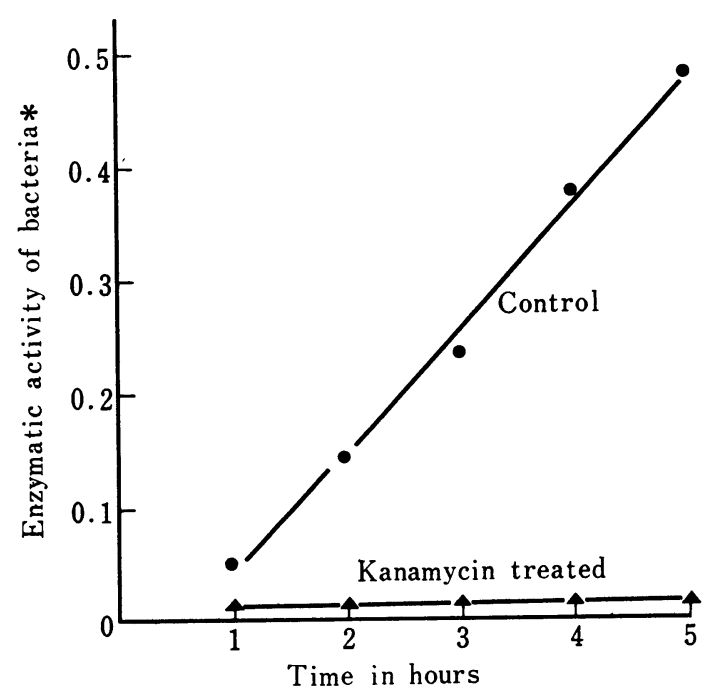

Fig. 4. Effect of kanamycin upon tetrazolium salt reducing activity of tubercle bacilli.

Note: * Optical density of ethyl acetate solution of reduced 2, 3, 5 triphenyltetrazolium chloride

amining the filtrate obtained through the cock. In addition to these observations, tetrazolium salt $(2,3,5$ triphenyltetrazolium chloride) reducing activity of the two cultures was compared in the presence of lactate according to our technique (Kanai and Yanagisawa, 1954). The test was conducted using $10 \mathrm{mg}$ of the bacilli, trichloracetic acid $(20 \%)$ for stopping the reaction, and ethyl acetate for extraction of formazan. The results obtained are presented in Figs. 2, 3 and 4. After drug contact, the bacillary growth was completely ceased and the number of cultivatable bacterial cells decreased near to $1 / 10000$ of the control culture. 
The hydrogen ion concentration of the treated culture remained at 7.8 during this experimental period, but that of the control culture decreased to 7.2. This observation may indicate that tubercle bacilli treated with kanamycin resist to autolysis even after the cease of multiplication.

The last experiment was made in order to isolate kanamycin-resistant variants of tubercle bacilli in a single step from a large inoculum of $\mathrm{H} 2$ and H37Rv strain. Dense bacillary suspensions were prepared from slant cultures of these strains on Ogawa medium. Serial ten-fold dilutions of these suspensions were inoculated in the amount of $0.1 \mathrm{cc}$ to the slants of Kirchner's agar medium without or with kanamycin in the concentrations of $1,5,10,50$, and $100 \mu \mathrm{g}$ per cc. After six week incubation at $37^{\circ} \mathrm{C}$, emergent colonies were counted. The results are presented in Table 1. Colonies appeared even in $100 \mu \mathrm{g}$ per cc medium inocu-

Table 1. Single step isolation of kanamycin-resistant variants from large inoculum of tubercle bacilli of $\mathrm{H} 2$ and $\mathrm{H} 37 \mathrm{Rv}$ strain

\begin{tabular}{|c|c|c|c|c|c|c|c|}
\hline \multirow{2}{*}{\multicolumn{2}{|c|}{ Size of inoculum }} & \multicolumn{6}{|c|}{ Concentration of kanamycin ( $\mu \mathrm{g}$ per cc) } \\
\hline & & 0 & 1 & 5 & 10 & 50 & 100 \\
\hline \multirow{4}{*}{$\mathrm{H} 2$} & Original & H & 㖄 & $H$ & $H$ & 21 & $6 *$ \\
\hline & $1: 10$ & 世 & 世 & + & + & 0 & 0 \\
\hline & $1: 10^{2}$ & m & + & 20 & 24 & 0 & 0 \\
\hline & $1: 10^{6}$ & 11 & 0 & 0 & 0 & 0 & 0 \\
\hline \multirow{4}{*}{ H37Rv } & Original & 世 & H & + & + & 0 & 0 \\
\hline & $1: 10$ & H & H & 4 & 8 & 0 & 0 \\
\hline & $1: 10^{2}$ & H & + & 0 & 0 & 0 & 0 \\
\hline & $1: 10^{6}$ & 15 & 0 . & 0 & 0 & 0 & 0 \\
\hline
\end{tabular}

Note: Each dilution was inoculated into kanamycin slauts in the amount of $0.1 \mathrm{cc}$.

For each kanamycin concentration, one slant was arranged.

$+, H, H$ mean the grade of *confluent growth.

* means the number of emergent solitary colonies in six week incubation at $37^{\circ} \mathrm{C}$.

lated with $\mathrm{H} 2$ strain, although in such an extremely rare rate as $1: 10^{6-7}$ sensitive cells. However, despite of almost the same size of inoculum, no colonies appeared on 50 and $100 \mu \mathrm{g}$ per cc medium inoculated with H37Rv strain. The colonies on $100 \mu \mathrm{g}$ per cc medium must be retested in order to confirm whether or not they are truly stable and established mutants resistant to this high concentration of kanamycin. But the observation above appears to indicate that kanamycin-resistance would develop in tubercle bacilli experimentally and perhaps also clinically.

Summary: Kanamycin has a certain degree of bactericidal effect, although being somewhat inferior to streptomycin. Colonies were obtained on $100 \mu \mathrm{g}$ per cc kanamycin medium in a single step from a large inoculum of a strain of tubercle bacilli (H2 strain). 


\section{REFERENCES}

Kanai, K. and Yanagisawa, K. (1954): Tetrazolium reduction test as a measure to examine the total viability of suspensions of tubercle bacilli, I. Studies on the technique of the test. Jap. J. M. Sc. \& Biol., 7, 155-167.

Yanagisawa, K. and Sato, N. (1957): Studies on kanamycin, a new antibiotic against tubercle bacilli, I. Effect on virulent tubercle bacilli in vitro and in mice. J. Antibiotics, Ser. A 10, 233-235.

Department of Tuberculosis, National

Kоомі KANAI,1)

Institute of Health, Tokyo5)

SHIGERU KATSUYAMA,2)

MAкото NAKAJIMA,3)

KEN YANAGISAWA4)

Received: August 31st, 1957

1) 金井興美・2)勝山茂・3) 中島誠・4) 柳沢謙, 5) 国立予防衛生研究所結核部 